Article

\title{
Chinese Cabbage Changes Its Release of Volatiles to Defend against Spodoptera litura
}

\author{
Yuan-Wen Du ${ }^{1,2,+} \mathbb{D}$, Xiao-Bin Shi ${ }^{3,+}$, Lin-Chao Zhao ${ }^{1,2}$, Ge-Ge Yuan ${ }^{1,2}$, Wei-Wei Zhao ${ }^{4}$, Guo-Hua Huang ${ }^{1,2, *}$ \\ and Gong Chen $1,2, *$
}

check for

updates

Citation: Du, Y.-W.; Shi, X.-B.; Zhao,

L.-C.; Yuan, G.-G.; Zhao, W.-W.; Huang, G.-H.; Chen, G. Chinese Cabbage Changes Its Release of Volatiles to Defend against Spodoptera litura. Insects 2022, 13, 73. https://doi.org/10.3390/ insects13010073

Academic Editors: Michael Moustakas and Stefanos Andreadis

Received: 17 December 2021

Accepted: 7 January 2022

Published: 10 January 2022

Publisher's Note: MDPI stays neutral with regard to jurisdictional claims in published maps and institutional affiliations.

Copyright: () 2022 by the authors Licensee MDPI, Basel, Switzerland. This article is an open access article distributed under the terms and conditions of the Creative Commons Attribution (CC BY) license (https:// creativecommons.org/licenses/by/ $4.0 /)$.
1 Hunan Provincial Key Laboratory for Biology and Control of Plant Diseases and Insect Pests, Hunan Agricultural University, Changsha 410128, China; duyuanwen112@163.com (Y.-W.D.); zhaolinchao946@163.com (L.-C.Z.); gegeyuan206@163.com (G.-G.Y.)

2 College of Plant Protection, Hunan Agricultural University, Changsha 410128, China

3 Hunan Plant Protection Institute, Hunan Academy of Agricultural Sciences, Changsha 410125, China; shixiaobin@hunaas.cn

4 Plant Protection and Quarantine Institution, Shimen County Agriculture and Rural Bureau, Changde 415399, China; smxzbzj@126.com

* Correspondence: ghhuang@hunau.edu.cn (G.-H.H.); gongchen105@163.com (G.C.)

+ These authors contributed equally to this work.

Simple Summary: Biological control is an important direction for pest control in the future, and chemical ecology is an indispensable part of biological control. Therefore, we tested the selection of Spodoptera litura and parasitic wasps on the volatiles of different treatments of cabbage and collected and analyzed the volatiles of different treatments of cabbage. This study found that cabbage was fed by Spodoptera litura to produce volatiles to avoid Spodoptera litura while also attracting Microplitis similis. As a result, some compounds were found to be related to the behavior of Spodoptera litura and Microplitis similis. These results provide a theoretical basis for searching for biological control resources and chemical control.

\begin{abstract}
Plants respond to herbivorous insect attacks by releasing volatiles that directly harm the herbivore or that indirectly harm the herbivore by attracting its natural enemies. Although the larvae of Spodoptera litura (the tobacco cutworm) are known to induce the release of host plant volatiles, the effects of such volatiles on host location by S. litura and by the parasitoid Microplitis similis, a natural enemy of $S$. litura larvae, are poorly understood. Here, we found that both the regurgitate of S. litura larvae and S. litura-infested cabbage leaves attracted M. similis. S. litura had a reduced preference for cabbage plants that had been infested with S. litura for 24 or $48 \mathrm{~h}$. M. similis selection of plants was positively correlated with the release of limonene; linalool and hexadecane, and was negatively correlated with the release of $(E)$-2-hexenal and 1-Butene, 4-isothiocyanato. S. litura selection of plants was positively correlated with the release of (E)-2-hexenal, 1-Butene, 4-isothiocyanato, and decanal, and was negatively correlated with the release of limonene, nonanal, hexadecane, heptadecane, and octadecane. Our results indicate that host plant volatiles can regulate the behavior of S. litura and M. similis.
\end{abstract}

Keywords: Chinese cabbage; plant-defense responses; Spodoptera litura; Microplitis similis

\section{Introduction}

Plants that are not infested with herbivorous insects emit only trace quantities of volatile organic compounds (VOCs). When infested by herbivores, in contrast, some plants emit large quantities of volatiles (herbivory-induced plant volatiles: HIPVs) [1], including terpenoids, green leaf volatiles, nitrogen-containing compounds, nitriles, oximes, aldehydes, alcohols, ketones, esters, ethers, and carboxylic acids [2,3]. These volatiles 
can be used to communicate with neighboring plants and insects, and they are also the precursors of plant defense measures.

Over a long period of coevolution, plants and insects have developed strategies to avoid each other's defense systems [4,5]. In response to attack by herbivorous insects, plants activate inducible defenses. Many of these inducible defenses directly target the herbivore's physiology and may protect the plant against further damage [6]. The induced insect resistance of plants is usually defined as direct or indirect according to the mode of action [7-9]. Direct modes of action involve the production of chemicals by the plant that directly harms the herbivore, whereas the indirect modes of action increase herbivore mortality through the recruitment of natural enemies [10-12]. Natural enemies of herbivores use HIPVs to locate their prey [13-16].

When acting as direct defenses, HIPVs can act as repellants or can reduce larval growth [17]. For example, maize leaves initially infested by Spodoptera exigua larvae can repel S. exigua and thereby reduce further damage [18]. When laying eggs, Spodoptera frugiperda females avoid tobacco plants that have been harmed by S. frugiperda [19]. HIPVs, however, can have different effects on different insects. For example, S. frugiperda larvae prefer to feed on maize leaves that have been infested by S. frugiperda larvae [20].

Regarding indirect defenses involving HIPVs, two natural enemies of the thrips Thrips tabaci, Amblyseius cucumeris, and Orius similis use volatiles released by thrips-damaged hosts to locate their prey [21]. The parasitoid Aphidius gifuensis, a natural enemy of Sitobion avenae, is more attracted to $S$. avenae-infested wheat than to non-infested wheat [22] Similarly, the parasitoid Cardiochiles nigriceps, a natural enemy of Heliothis virescens but not of Helicoverpa zea, uses plant volatiles to distinguish between $H$. virescens- and $H$. zea-infested plants [23]. Furthermore, intermittent exposure to the volatiles emitted from artificially damaged Arabidopsis has been shown to induce defensive responses in undamaged neighboring plants [24].

The current research concerns the effects of HIPVs on S. litura and M. similis. S. litura is a serious pest, i.e., its larvae consume the leaves of tobacco and many other valuable crop plants. Although HIPVs are known to increase the attractiveness of sex pheromone lures used to trap S. litura adults, little is known about the effects of HIPVs on the feeding behavior of S. litura larvae [25]. The larvae of $S$. litura are hosts for the parasitoid wasp $M$. similis, which is an important biological control agent of the herbivore. M. similis can reduce the weight gain and feed intake of the $S$. litura larvae and can increase larval mortality [26,27]. In addition, M. similis is a vector of insect ascoviruses-vesicle virus. The "bee-venom" coordinated control mode can expand the spread radius of the virus in the host population, thereby greatly improving the spread of $M$. similis biological control effect [28]. In the current research, we assessed the responses of S. litura and M. similis to HIPVs released by Chinese cabbage leaves or cabbage plants that had been treated in one of six ways, i.e., they were healthy, mechanically damaged, coated with the regurgitate of S. litura larvae or infested with S. litura larvae for 12,24 , or $48 \mathrm{~h}$.

\section{Materials and Methods}

\subsection{Plant Material}

Chinese cabbage plants (Ju Hong Xin) were grown in a greenhouse at $20 \pm 5{ }^{\circ} \mathrm{C}$ and with a $12 \mathrm{~h}: 12 \mathrm{~h}$ light:dark photoperiod at the Hunan Provincial Key Laboratory for Biology and Control of Plant Diseases and Insect Pests. Experiments included six kinds of plants (all with six fully expanded leaves) or leaves from such plants: undamaged healthy leaves (HP), mechanically damaged plants (MDP: obtained by scratching the leaves of healthy plants 5 times with an insect needle), plants that were dipped in a $5 \%$ solution of S. litura "regurgitate" (RTP: see next section) for $12 \mathrm{~h}$ [29], and plants that were infested with secondto third-instar larvae of S. litura (SIP: 1 larva per leaf) for $12 \mathrm{~h}, 24 \mathrm{~h}$, or $48 \mathrm{~h}$. 


\subsection{Insect}

Specimens of the cotton leafworm S. litura were collected from the experimental field of Hunan Agricultural University; M. similis was collected in a cotton field near Hunan Agricultural University, Changsha, Hunan, China. S. litura eggs and M. similis were obtained from our laboratory. M. similis were reared from $S$. litura larvae as the host. They were reared in a chamber at $27 \pm 2{ }^{\circ} \mathrm{C}, \mathrm{RH}=70 \pm 10 \%$, and a $14 \mathrm{~h}: 10 \mathrm{~h} \mathrm{~L}$ : $\mathrm{D}$ photoperiod. Regurgitate from third- to fourth-instar larvae of $S$. litura were collected by gently squeezing the larvae manually and placing a pipette tip on their mouthparts. The regurgitated material was then transferred to Eppendorf tubes and stored at $-80^{\circ} \mathrm{C}$.

\subsection{Olfactory Preferences of M. similis (M. similis Olfactometer Experiments 1-4)}

We used a 4-arm olfactometer [30] with one glass sample bottle per arm to assess the olfactory preferences of 3-day-old mated females of $M$. similis. Each of the first three experiments included two empty sample bottles (blanks) and one bottle containing an undamaged, healthy plant. The fourth bottle in experiments 1-3 contained a mechanically damaged plant, a plant treated with larval regurgitate, or a plant infested with S. litura for $12 \mathrm{~h}$, respectively. In experiment 4 , the sample bottles contained a healthy plant, a mechanically damaged plant, a plant treated with larval regurgitate, or a plant infested with $S$. litura for $12 \mathrm{~h}$. Each assay with four sample bottles was replicated 30 times.

The trap ball was attached above the four selection arms; for each $M$. similis individual, the selection was indicated by its climbing into the trap ball. An LED tube was hung $18.0 \mathrm{~cm}$ above an olfactometer, which was placed under a white canvas cover to diffuse the light source from interfering with the selection behavior of the wasps. In the experiment, a medical air compressor with low noise and relatively pure gas was selected as the gas delivery device, and a three-stage oil-water separator was used to filter out impurities in the gas, and then a clean and moist gas was produced after passing it into the filter bottle. By controlling the air compressor, the total gas flow rate is controlled at about $2.5 \mathrm{~L}$ $\mathrm{min}^{-1}$, and the rotor flow device is adjusted to control the airflow rate through each gas source bottle at about $500 \mathrm{~mL} \mathrm{~min}^{-1}$. Individual airflow was connected to each odor source and converged to a central glass piece where $4 \mathrm{M}$. similis females were released. After thirty minutes following release, the location of each of the wasps was noted. Selection for an odor source was concluded when a wasp was present in one of the four ball traps. The experiment was replicated thirty times with 4 female wasps each time. Between replicates, glassware was cleaned by sequential rinsing in water, acetone, and pentane, after which the glassware was placed in an oven at $250{ }^{\circ} \mathrm{C}$ for $3 \mathrm{~h}$.

2.4. Behavioral Responses of S. litura Larvae to Chinese Cabbage and Volatile Compounds (S. litura Petri Dish Experiments 1 and 2, and S. litura Olfactometer Experiments 1 and 2)

The preferences of S. litura larvae for leaves treated in the indicated ways were compared in Petri dishes $(20 \mathrm{~cm}$ diameter) containing a piece of filter paper with a drawn line that separated the dish into two equal sides. The experiments were conducted at $28 \pm 1{ }^{\circ} \mathrm{C}$ and in the dark. In Petri dish experiment 1 , the following treatments were compared: CK (blank treatment without plants) vs. healthy leaves, and CK vs. leaves that had been infested by $\mathrm{S}$. litura for $12,24 \mathrm{~h}$, or $48 \mathrm{~h}$. In Petri dish experiment 2 , the following treatments were compared: healthy leaves vs. leaves that had been infested by $S$. litura for $12,24 \mathrm{~h}$, or $48 \mathrm{~h}$ (the infesting larvae were removed from the leaves immediately before the experiment began). In each replicate of each treatment of the Petri dish experiments, one secondto third-instar larvae of S. litura that had been starved for $24 \mathrm{~h}$ was placed in the center of the dish, and its feeding selection was recorded at $15 \mathrm{~min}$. After a larva made a selection, it was removed, and the original leaf was immediately replaced with a new leaf for the next larva to choose. The Petri dish and filter paper were replaced every 3 larvae. The Petri dish experiments were conducted 3 times, each time with 30 replicates per treatment.

A glass Y-tube olfactometer, consisting of a $12 \mathrm{~cm}$ long base tube and two $16 \mathrm{~cm}$ long arms at a $60^{\circ}$ angle with an inner diameter of $2.0 \mathrm{~cm}$, was used to observe the olfactory 
response of $S$. litura larvae to the volatiles of cabbage leaves. Before the start of each assay, we treated the system with compressed air for $10 \mathrm{~min}$ to ensure that the odors in the arms were equivalent. By controlling the air compressor and rotameter, we controlled the gas flow rate at $300 \mathrm{~mL} \mathrm{~min}^{-1}$ and leading to the two arms of the olfactory instrument. Under dark conditions and at $28 \pm 1{ }^{\circ} \mathrm{C}$, we released one third-instar larva of S. litura at the base of the straight tube. At $20 \mathrm{~min}$ from the time of release, if the $S$. litura larva moved half the length of either arm, it was considered to have made a choice. If the larva had not moved half the length of an arm within $20 \mathrm{~min}$, it was recorded as "no choice". Plants were changed, and glassware was cleaned every five insects made a choice. The treatments and replicate are the same as the Petri dish experiment.

\subsection{Collection and Analysis of Volatiles via Solid Phase Microextraction}

The commercial fiber DVB/CAR/PDMS 50/30 $\mu \mathrm{m}$ (SAAB-57328U, Supelco, Inc., Bellefonte, PA, USA) was mounted in an SPME manual holder (SAAB-57330U, Supelco, Inc., Bellefonte, PA, USA). For each analysis, $5 \mathrm{~g}$ of sample was placed in a $40-\mathrm{mL}$ vial and was spiked with $0.02 \mathrm{~mL}$ of an internal standard (11.03 g/L heneicosane). After each vial was placed at $30^{\circ} \mathrm{C}$ to equilibrate, the septum was pierced with the SPME needle. Fibers were exposed to the sample headspace for $60 \mathrm{~min}$. After the extraction time, fibers were retracted into the needle, immediately transferred to the injection port of a GC, and desorbed at $230{ }^{\circ} \mathrm{C}$ for $1 \mathrm{~min}$.

VOCs were analyzed with a GC connected to a mass spectrometer (MS) (Agilent 7890A-5975C). Separation was carried out on a Supelcowax 10 fused silica capillary column $30 \mathrm{~m} \times 0.25 \mathrm{~mm}$ ID $\times 0.25 \mu \mathrm{m}$ film thickness (Agilent J\&W DB-5MS). On the DB-5 ms column, the initial oven temperature was kept at $60^{\circ} \mathrm{C}$ for $2 \mathrm{~min}$ and was then increased to $100{ }^{\circ} \mathrm{C}$ at a programmed rate of $3{ }^{\circ} \mathrm{C} \min ^{-1}$ and then to $190{ }^{\circ} \mathrm{C}$ at a rate of $2{ }^{\circ} \mathrm{C} \min ^{-1}$. The inlet was operated in splitless injection mode, and the injector temperature was maintained at $220{ }^{\circ} \mathrm{C}$ with a constant flow rate of $2.0 \mathrm{~mL} \mathrm{~min}{ }^{-1}$. The mass spectra were scanned at $70 \mathrm{eV}$ over a mass range from $m / z 40$ to 450 . The quantities of the major components of the blends were estimated based on the peak areas of the compounds compared to the peak areas of the internal standards. Compounds were identified by comparing the spectra obtained from the samples with those from a reference database (NIST mass spectral library).

\subsection{Statistical Analysis}

Before analysis, data were checked for normality and homogeneity of variance; data were log-transformed as needed. The raw data were sorted with Microsoft Excel 2016 and were then analyzed with SPSS 22.0 software (IBM SPSS Statistics 22.0). The data concerning the effects of treatments on the selection of $S$. litura were compared with the Chi-square test $(p<0.05)$. Data of $M$. similis experiments $1-4$ and the release amount from leaves of different treatments were carried out by one-way ANOVA with post-hoc contrasts by Tukey's honestly significant difference test $(\alpha=0.05)$. The relationship between volatile release and host searching behavior of $M$. similis and S. litura was analyzed by SPSS software, and the Pearson correlation coefficient was used to analyze the correlation after the data basically conformed to linear correlation, normal distribution, and no abnormal value. The figures were plotted using GraphPad Prism 8 (GraphPad Software, San Diego, CA, USA).

\section{Results}

\subsection{Olfactory Preferences of M. similis (M. similis Olfactometer Experiments 1-4)}

The attraction of $M$. similis significantly differed among treatments in the four experiments. In the first experiment, the attraction of $M$. similis did not differ for healthy and mechanically damaged plants, but both were more attractive than the blank odor source $(p<0.05$; Figure 1a). In the second experiment, plants treated by $S$. litura regurgitate were much more attractive than healthy plants or the blank odor source $(p<0.05$; Figure $1 b)$. In the third experiment, plants infested by $S$. litura larvae were much more attractive than 
healthy plants or the blank odor source $(p<0.05$; Figure $1 \mathrm{c})$. In the last experiment, plants infested by $S$. litura larvae were the most attractive, mechanically damaged plants, and the blanks odor source were the least attractive, and plants treated with $S$. litura regurgitate were intermediate in their attractiveness $(p<0.05$; Figure $1 \mathrm{~d})$.

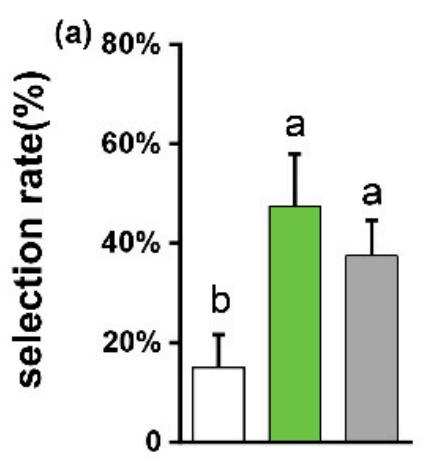

(b) 8

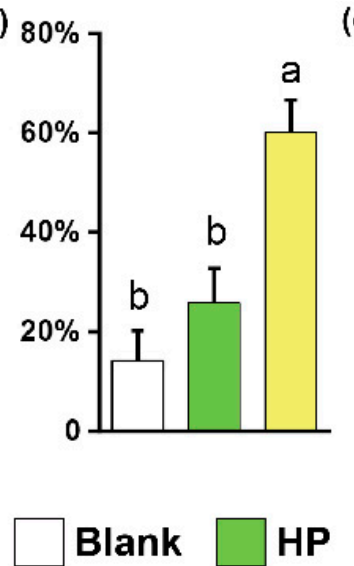

(c) $80 \%$

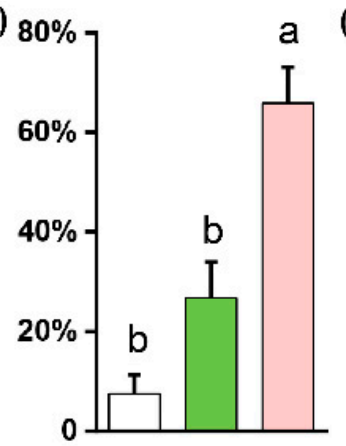

(d) $60 \%$

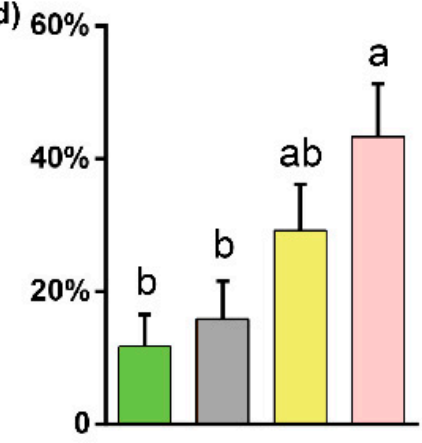

Figure 1. Percentage of $M$. similis females attracted to treatments in a four-arm olfactometer. Preference of $M$. similis for (a) Mechanically damaged vs. healthy plants and blanks (M. similis olfactometer experiment (1); (b) RTP-treated plants vs. healthy plants and blanks (M. similis olfactometer experiment (2); (c) Plants infested with S. litura for $12 \mathrm{~h}$ vs. healthy plants and blanks (M. similis olfactometer experiment (3), and (d) Mechanically damaged, RTP-treated, S. litura-infested, and healthy plants (M. similis olfactometer experiment (4). Blank: empty odor source (no plants); HP: healthy plants; MDP: mechanically damaged plants; RTP: "regurgitate"-treated plants; SIP: S. litura-infested plants. Values are means + SE. Bars labeled with different letters are significantly different by Tukey's HSD test $(p<0.05$; one-way ANOVA, $\alpha=0.05)$.

3.2. Feeding and Olfactory Selecting Behavior of S. litura Larvae (S. litura Petri Dish Experiment 1 and 2, and S. litura Olfactometer Experiments 1 and 2)

In the first Petri dish experiment, $S$. litura preferred healthy leaves over no leaves (blank) and preferred S. litura-infested leaves over no leaves (blank) $(p<0.001$; Figure 2a). In the second Petri dish experiment, $S$. litura larvae showed no significant preference for healthy leaves vs. leaves that had been infested with $S$. litura for $12 \mathrm{~h}$; as the infestation time increased to 24 and $48 \mathrm{~h}$; however, S. litura clearly preferred healthy leaves over S. litura-infested leaves (Figure 2b). In "Y" type olfactometer experiments, the selection rate of healthy plants and of S. litura-infested plants was significantly higher than that of no plant, but an increase in the infestation time tended to decrease the selection of infested plants ( $p<0.01$; Figure $2 c)$, S. litura larvae showed no significant preference between healthy plants and plants that had been infested with S. litura for 12 h; however, S. litura larvae clearly preferred healthy plants over plants that had been infested with S. litura for 24 and 48 h $(p<0.001$; Figure 2d).

\subsection{Quantities of Total and Six Classes of Volatiles Released}

The quantity of volatiles collected and identified was highest for plants infested with S. litura for $48 \mathrm{~h}$ was lowest for undamaged plants, mechanically damaged plants, and regurgitate-treated plants; and was intermediate for plants infested with S. litura for $12 \mathrm{~h}$ and $24 \mathrm{~h}(p<0.05$; Figure 3$)$. 

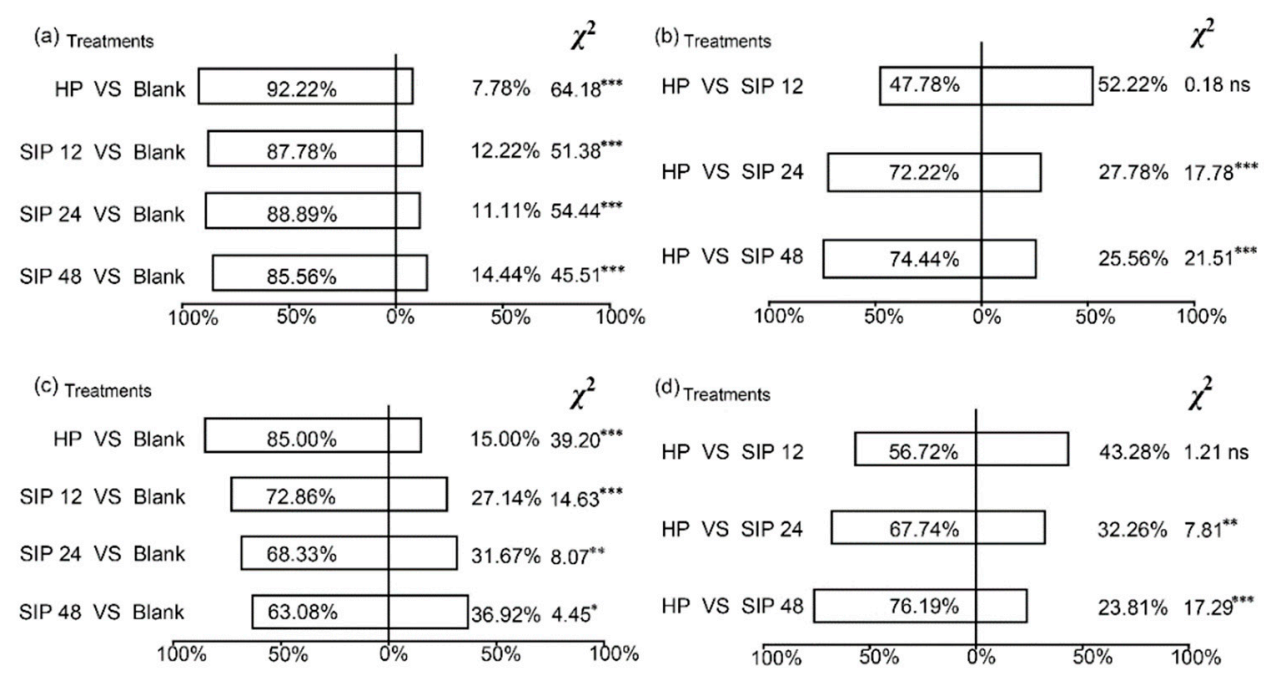

Figure 2. Percentage of $S$. litura attracted to no plants (blank), healthy Chinese cabbage plants (HP), plants infested with S. litura (SIP; for 12, 24, or 48 h) in S. litura Petri dish experiments 1 (a) and 2 (b) and in S. litura olfactometer experiments 1 (c) and 2 (d). ${ }^{*}, * * * * *$, and ns indicate $p<0.05,<0.01$, $<0.001$, and not significant, respectively, according to a $\chi^{2}$ test.

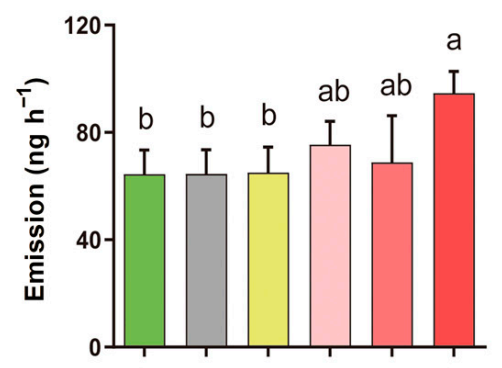

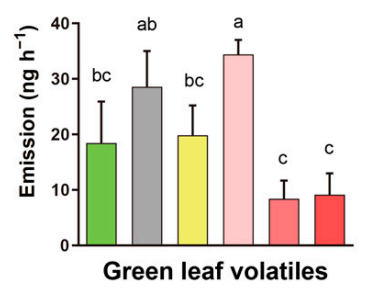

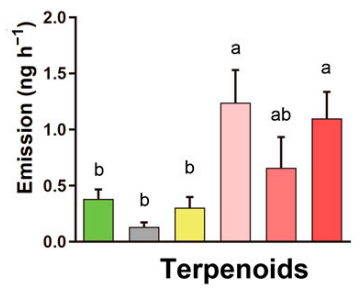

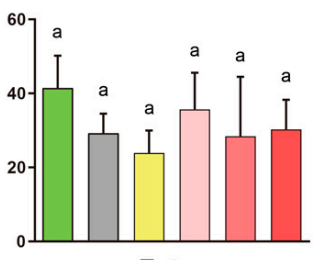

Esters

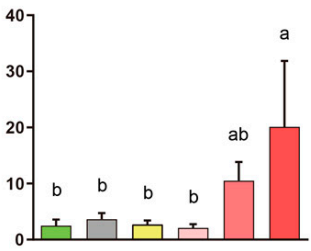

Ketones
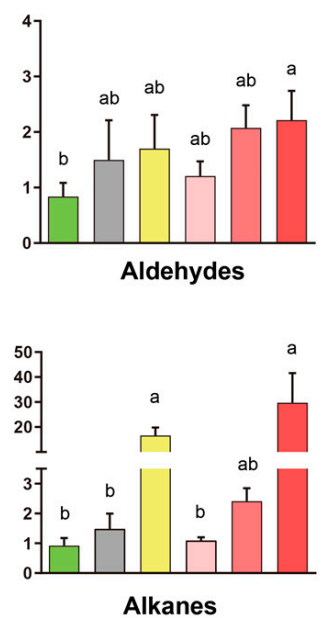

$\square$ HP $\square$ MDP $\square$ RTP $\square$ SIP $12 \square$ SIP $24 \square$ SIP 48

Figure 3. Total quantities of volatile organic compounds (VOCs) released by Chinese cabbage plants in response to six treatments. Total quantities of six classes of volatiles released by Chinese cabbage plants in response to six treatments. HP: healthy plants; MDP: mechanically damaged plants; RTP: regurgitate-treated plants; SIP: plants infested with S. litura for 12, 24, or $48 \mathrm{~h}$. Values are means + SE. Bars labeled with different letters are significantly different by Tukey's HSD test $(p<0.05$; one-way ANOVA, $\alpha=0.05)$. 
The volatiles were assigned to the following six main classes of HIPVs in Brassicaceae [31]: green leaf volatiles, ester, aldehydes, terpenoids, ketones, and alkanes (Figure 3). The release of esters, aldehydes, and ketones by Chinese cabbage did not significantly differ between healthy plants vs. mechanically damaged plants or plants infested with $S$. litura for $12 \mathrm{~h}$. There was no significant difference in the release of any class of volatiles between healthy and mechanically damaged plants. The regurgitate treatment increased the release of alkanes but not of other volatiles. The emission of terpenoids, ketones, and alkanes tended to increase, but the emission of green leaf volatiles decreased with the increase in S. litura infestation time.

\subsection{Quantities of 16 Specific Compounds Released}

GC-MS analysis of the headspace volatiles produced by each treatment of Chinese cabbage detected 17 compounds (Table S1). Geranyl acetone has been compared with other categories mentioned above, and we have compared the release of the remaining 16 compounds. (Figure 4): (E)-2-hexenal; (Z)-3-henxen-1-ol; butane,1-isothiocyanato; 1-Butene,4isothiocyanato; (Z)-3-hexenyl acetate; limonene; ally isothiocyanate; linalool; nonanal; decanal benzyl isothiocyanate; tetradecane; pentadecane; hexadecane; heptadecane; octadecane. Butane,1-isothiocyanato was not detected in the S. litura regurgitate treatment, and limonene was only detected from S. litura-infested plants. The release of nonanal was increased by $S$. litura infestation for 24 and $48 \mathrm{~h}$ and tended to be increased by mechanical damage, regurgitate, and $S$. litura infestation for $12 \mathrm{~h}$. Regurgitate increased the release of nonanal, pentadecane, and heptadecane but reduced the release of butane,1-isothiocyanato, 1-Butane,4-isothiocyanato, and ally isothiocyanate. S. litura infestation increased the release of pentadecane and heptadecane, but the release of 1-Butane,4-isothiocyanato and decanal. The effect of $S$. litura infestation varied with infestation time. S. litura infestation for $12 \mathrm{~h}$ increased the release of (Z)-3-hexen-1-ol, butane,1-isothiocyanato, (Z)-3-hexenylacctate, limonene; allyisothiocyanate, linalool, nonanal, and henxadecane, the release of these compounds was decreased; however, by S. litura infestation for $24 \mathrm{~h}$. The quantity of (E)-2-hexenal released was lower for plants infested with $S$. litura for $12 \mathrm{~h}$ than for healthy plants, and (E)-2-hexenal was not detected from plants infested with S. litura infested for 24 and $48 \mathrm{~h}$. Butane,1-isothiocyanato was also not detected from plants infested with S. litura for 24 or $48 \mathrm{~h}$.

\subsection{Relationships between the Release of Classes of Volatiles and the Host Searching Behavior of} M. similis and $S$. litura

Linear regression was used to analyze the linear relationships between the quantities of classes of volatile emissions and the selection rate of $M$. similis and S. litura. According to linear regression, the $M$. similis selection rate was positively related to the release of terpenoids $(p<0.05$, Table 1$)$.

According to linear regression, the selection rate of $S$. litura was positively related to the release of esters but was negatively related to the release of aldehydes and ketones $(p<0.05$, Table 1$)$.

\subsection{Relationship between the Release of Specific Volatiles by Chinese Cabbage and the Host Searching Behavior of $M$. similis and S. litura}

According to linear regression, the $M$. similis selection rate was positively related with the release of limonene, linalool, and hexadecane but was negatively related with the release of $(E)$-2-hexenal and 1-Butene, 4-isothiocyanato $(p<0.05$, Table 2$)$. 

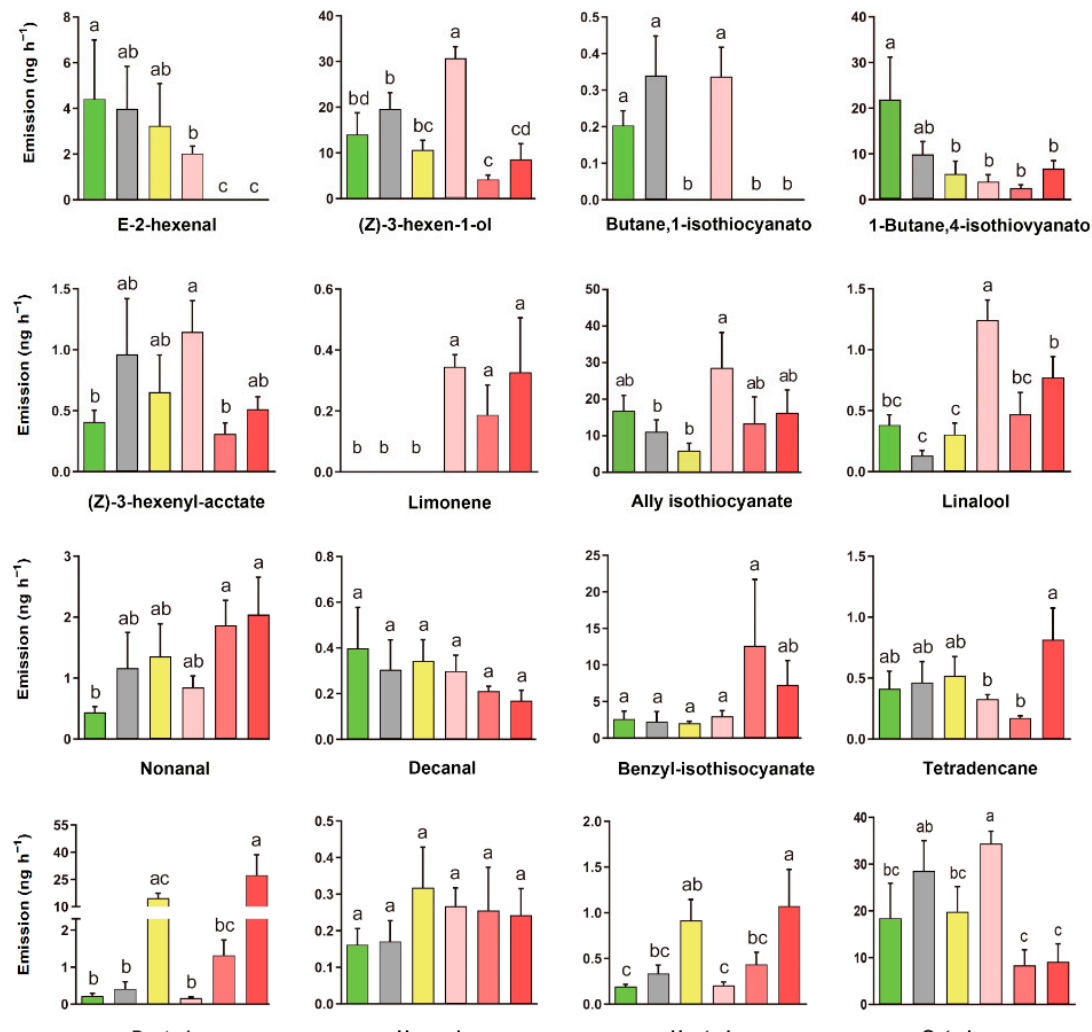

$\square$ HP $\square$ MDP $\square$ RTP $\square$ SIP $12 \square$ SIP $24 \square$ SIP 48

Figure 4. Quantities of specific volatiles released by Chinese cabbage plants in response to six treatments. HP: healthy plants; MDP: mechanically damaged plants; RTP: regurgitate-treated plants; SIP: plants infested with $S$. litura for 12, 24, or $48 \mathrm{~h}$. Values are means + SE. Bars labeled with different letters are significantly different by Tukey's HSD test $(p<0.05$; one-way ANOVA, $\alpha=0.05)$.

Table 1. Linear relationships between quantities of classes of volatiles emitted by Chinese cabbage plants under different treatments and the selection rates of M. similis and S. litura.

\begin{tabular}{cccc}
\hline Class & Linear Regression Equation & $\boldsymbol{R}^{2}$ & $\boldsymbol{p}$ \\
\hline \multirow{2}{*}{ Green leaf volatiles } & $\mathrm{y}_{1}=0.0122 \mathrm{x}-0.0576$ & 0.3775 & 0.6542 \\
\cline { 2 - 4 } & $\mathrm{y}_{2}=0.0031 \mathrm{x}+0.6681$ & 0.1609 & 0.5782 \\
\hline \multirow{2}{*}{ Esters } & $\mathrm{y}_{1}=-0.1427 \mathrm{x}+0.6413$ & 0.3946 & 0.5084 \\
\cline { 2 - 4 } & $\mathrm{y}_{2}=0.0148 \mathrm{x}+0.2220$ & 0.8530 & 0.0382 \\
\hline \multirow{2}{*}{ Aldehydes } & $\mathrm{y}_{1}=0.0963 \mathrm{x}+0.1238$ & 0.0587 & 0.1475 \\
\hline \multirow{2}{*}{ Terpenoids } & $\mathrm{y}_{2}=-0.1305 \mathrm{x}+0.9298$ & 0.8681 & 0.0259 \\
\cline { 2 - 4 } & $\mathrm{y}_{1}=0.2537 \mathrm{x}+0.1194$ & 0.7103 & 0.0443 \\
\hline \multirow{2}{*}{ Ketones } & $\mathrm{y}_{2}=-0.1545 \mathrm{x}+0.8538$ & 0.4286 & 0.3579 \\
\cline { 2 - 4 } & $\mathrm{y}_{1}=-0.0035 \mathrm{x}+0.3651$ & 0.0326 & 0.2442 \\
\hline \multirow{2}{*}{ Alkanes } & $\mathrm{y}_{2}=-0.0091 \mathrm{x}+0.8029$ & 0.6722 & 0.0182 \\
\cline { 2 - 4 } & $\mathrm{y}_{1}=0.0037 \mathrm{x}+0.2313$ & 0.0372 & 0.4786 \\
\hline
\end{tabular}

Pearson correlation coefficient $\left(R^{2}\right)$ between different classes of volatiles released and selection rate of M. similis and S. litura. " $\mathrm{x}$ " in the equations represents the number of different classes of volatiles released. " $\mathrm{y}_{1}$ " represents the selection rate of $M$. similis as affected by treatments. " $\mathrm{y}_{2}$ " represents the selection rate of S. litura as affected by treatments, significantly correlation at $p<0.05$. 
Table 2. Linear relationships between quantities of specific volatiles emitted by Chinese cabbage plants under different treatments and the selection rates of $M$. similis and S. litura.

\begin{tabular}{|c|c|c|c|c|}
\hline Number & Compound & $\begin{array}{c}\text { Linear Regression } \\
\text { Equation }\end{array}$ & $R^{2}$ & $p$ \\
\hline \multirow{2}{*}{1} & \multirow{2}{*}{ E-2-hexenal } & $\mathrm{y}_{1}=-0.1582 \mathrm{x}+0.7733$ & 0.9729 & 0.0118 \\
\hline & & $\mathrm{y}_{2}=0.0471 \mathrm{x}+0.6524$ & 0.9286 & 0.0195 \\
\hline \multirow{2}{*}{2} & \multirow{2}{*}{ (Z)-3-hexen-1-ol } & $\mathrm{y}_{1}=0.0106 \mathrm{x}+0.0504$ & 0.3947 & 0.0931 \\
\hline & & $y_{2}=0.0025 x+0.6880$ & 0.0926 & 0.6650 \\
\hline \multirow{2}{*}{3} & \multirow{2}{*}{$\begin{array}{c}\text { Butane, } \\
\text { 1-isothiocyanato }\end{array}$} & $\mathrm{y}_{1}=0.0308 \mathrm{x}+0.2432$ & 0.0011 & 0.4750 \\
\hline & & $\mathrm{y}_{2}=0.3384 \mathrm{x}+0.6775$ & 0.3567 & 0.3794 \\
\hline \multirow{2}{*}{4} & \multirow{2}{*}{$\begin{array}{c}\text { 1-Butene, } \\
\text { 4-isothiocyanato }\end{array}$} & $\mathrm{y}_{1}=-0.0148 \mathrm{x}+0.4032$ & 0.6497 & 0.0320 \\
\hline & & $y_{2}=0.0087 x+0.6470$ & 0.6842 & 0.0164 \\
\hline \multirow{2}{*}{5} & \multirow{2}{*}{ (Z)-3-hexenyl acetate } & $\mathrm{y}_{1}=0.2949 \mathrm{x}+0.0161$ & 0.4216 & 0.9269 \\
\hline & & $\mathrm{y}_{2}=-0.0011 \mathrm{x}+0.7239$ & 0.0003 & 0.9830 \\
\hline \multirow{2}{*}{6} & \multirow{2}{*}{ Limonene } & $\mathrm{y}_{1}=0.1476 \mathrm{x}+0.1863$ & 0.7317 & 0.0230 \\
\hline & & $\mathrm{y}_{2}=-0.4678 \mathrm{x}+0.8237$ & 0.6379 & 0.0123 \\
\hline \multirow{2}{*}{7} & \multirow{2}{*}{ Allyl isothiocyanate } & $\mathrm{y}_{1}=0.0083 \mathrm{x}+0.1218$ & 0.2929 & 0.4685 \\
\hline & & $y_{2}=0.0018 x+0.6892$ & 0.0170 & 0.8381 \\
\hline \multirow{2}{*}{8} & \multirow{2}{*}{ Linalool } & $\mathrm{y}_{1}=0.2530 \mathrm{x}+0.1196$ & 0.7105 & 0.0132 \\
\hline & & $\mathrm{y}_{2}=-0.0775 \mathrm{x}+0.7788$ & 0.1037 & 0.7103 \\
\hline \multirow[t]{2}{*}{9} & \multirow{2}{*}{ Nonanal } & $\mathrm{y}_{1}=0.0929 \mathrm{x}+0.1616$ & 0.0626 & 0.1375 \\
\hline & & $\mathrm{y}_{2}=-0.1147 \mathrm{x}+0.8738$ & 0.8862 & 0.0179 \\
\hline \multirow{2}{*}{10} & \multirow{2}{*}{ Decanal } & $\mathrm{y}_{1}=-1.870 \mathrm{x}+0.8797$ & 0.3402 & 0.5150 \\
\hline & & $\mathrm{y}_{2}=0.9045 \mathrm{x}+0.4791$ & 0.9739 & 0.0083 \\
\hline \multirow{2}{*}{11} & \multirow{2}{*}{ Benzyl isothiocyanate } & $\mathrm{y}_{1}=0.1529 \mathrm{x}-0.1278$ & 0.1784 & 0.1890 \\
\hline & & $\mathrm{y}_{2}=-0.0126 \mathrm{x}+0.8033$ & 0.3965 & 0.3324 \\
\hline \multirow{2}{*}{12} & \multirow{2}{*}{ Tetradecane } & $\mathrm{y}_{1}=-0.8443 \mathrm{x}+0.6144$ & 0.2143 & 0.9933 \\
\hline & & $\mathrm{y}_{2}=-0.1241 \mathrm{x}+0.7769$ & 0.1323 & 0.6718 \\
\hline \multirow{2}{*}{13} & \multirow{2}{*}{ Pentadecane } & $\mathrm{y}_{1}=0.0039 \mathrm{x}+0.2349$ & 0.0356 & 0.4825 \\
\hline & & $\mathrm{y}_{2}=-0.0047 \mathrm{x}+0.7575$ & 0.4602 & 0.3447 \\
\hline \multirow{2}{*}{14} & \multirow{2}{*}{ Hexadecane } & $\mathrm{y}_{1}=1.7680 \mathrm{x}-0.1478$ & 0.6716 & 0.0163 \\
\hline & & $\mathrm{y}_{2}=-1.560 \mathrm{x}+1.085$ & 0.6310 & 0.0205 \\
\hline \multirow[t]{2}{*}{15} & \multirow[t]{2}{*}{ Heptadecane } & $\mathrm{y}_{1}=0.0553 \mathrm{x}+0.2272$ & 0.0161 & 0.4896 \\
\hline & & $\mathrm{y}_{2}=-0.1963 \mathrm{x}+0.8132$ & 0.6293 & 0.0228 \\
\hline 16 & Octadecane & $\mathrm{y}_{1}=0.4606 \mathrm{x}+0.1868$ & 0.0128 & 0.2183 \\
\hline & & $\mathrm{y}_{2}=-0.9494 \mathrm{x}+0.9098$ & 0.5175 & 0.0263 \\
\hline
\end{tabular}

Pearson correlation coefficient $\left(R^{2}\right)$ between different classes of volatiles released and selection rate of $M$. similis and S. litura. " $\mathrm{x}$ " in the equations represents the quantity of specific volatiles released. " $\mathrm{y}_{1}$ " represents the selection rate of $M$. similis as affected by treatments, and " $\mathrm{y}_{2}$ " represents the selection rate of S. litura as affected by treatments, significantly correlation at $p<0.05$.

According to linear regression, the selection rate of $S$. litura was positively related with the release of (E)-2-hexenal, 1-Butene, 4-isothiocyanato, and decanal but was negatively related with the release of limonene, nonanal, hexadecane, heptadecane, and octadecane $(p<0.05$, Table 2$)$. 


\section{Discussion}

The tritrophic interactions among plants, herbivores, and their parasitoids and influence each other in the long course of coevolution [12]. Plants use an array of biochemical and morphological properties to defend against attacks by herbivores. For direct defense, plants produce organic compounds that interfere with the behavior of herbivores $[10,32,33]$. For indirect defense, the HIPVs produced by plants can attract natural enemies of herbivores $[6,9,23,34]$. This study shows that Chinese cabbage releases volatiles that can suppress $S$. litura larvae from choosing leaves that are already exploited. However, when the larvae choose to feed on unattacked leaves, they face the risk of being found by M. similis. These patterns support the proposition that plants have evolved to manipulate the blend of volatiles that are emitted in order to maximize both direct and indirect defenses against herbivory.

Olfactory receptors can be used by herbivorous insects to help locate hosts or to avoid danger [35-38]. Studies on the oviposition behavior of S. litura have shown that the adults of $S$. litura can rely on plant volatiles to find the most suitable hosts but to avoid plants already infested by $S$. litura larvae $[39,40]$. Before the current study, however, little was known about how host plant volatiles affects the feeding of $S$. litura larvae. We found that $S$. litura larvae prefer undamaged to damaged cabbage tissue and showed significant responses to HIPVs (Figure 2b,d). The characteristics of this feeding behavior are consistent with those of other Noctuidae insects. S. exigua, for example, showed obvious antifeedant and evasive responses to corn HIPVs [17].

In the current study, we found that M. similis females were attracted to both S. litura regurgitate-treated plants and S. litura-infested plants, but when given a choice among volatiles produced by healthy, mechanically damaged, regurgitate-treated, and S. liturainfested plants, they strongly preferred volatiles produced by S. litura-infested plants (Figure 1). In response to damage caused by herbivorous insects, plants can regulate lipoxygenase, isoprenoid, and shikimate pathways in order to release compounds that attract natural enemies of herbivores for indirect defense [41]. This phenomenon has been previously reported. When infested by S. exigua, for example, Zea mays, Nicotiana tabacum, and Gossypium hirsutum release volatiles that attract wasps that parasitize S. exigua $[13,23,42]$.

To determine whether a single factor in S. litura larval feeding affects the behavior of parasitic wasps, we simulated the effects of mechanical damage and herbivore regurgitate on the behavior of $M$. similis. We found that, compared with responses to clean air, M. similis females showed strong responses to the volatiles of regurgitate-treated plants but not to the volatiles of mechanically damaged plants (Figure 1a,b). Mechanical damage to plants also failed to attract Microplitis palidipes [43]. When comparing the effects of the treatments on the release of classes of volatiles, we found that there was no significant difference between the mechanical damage treatment and the healthy treatment, but that the $S$. litura regurgitate treatment reduced the release of aldehydes and alkanes (Figure 3). We found that the S. litura regurgitate treatment reduced the release of butane,1-isothiocyanato and 1-Butene,4-isothiocyanato, and increased the release of nonanal, pentadecane, and heptadecane (Figure 4). A reduction in the release of specific volatiles by plants has also been found for other Noctuidae. For example, glucose oxidase in Helicoverpa zea regurgitate can reduce the release of nicotine in tobacco [44]. In another study, the regurgitate of $S$. frugiperda reduced the release of corn HIPVs but did not affect the attraction of the parasitoid Cotesia marginiventris to S. frugiperda-infested corn [45]. As part of their long-term coevolution with host plants, herbivores may reduce the release of HIPVs so as to reduce the indirect defense involving the attraction of natural enemies.

To simulate the feeding of S. litura in the current study, we simply soaked the plants in regurgitate. The total amount of volatiles released was smaller after regurgitate treatment than after larval infestation (Figure 3), which is reasonable because S. litura larvae will both produce regurgitate and destroy a substantial quantity of host plant tissue. According to the results discussed above, we speculate that the backflow of S. litura may have elicitors to 
change the volatiles of Chinese cabbage, and the induced volatiles will affect the selection behavior of $M$. similis.

Previous studies have shown that the length of time that plants are infested by herbivorous insects will affect the diversity and richness of HIPVs $[1,46,47]$. For example, tomato plants released more (3Z)-3-hexen-1-yl acetate, $\beta$-ocirene, and $\beta$-caryophyllene after $12 \mathrm{~h}$ than after $6 \mathrm{~h}$ of Trichoplusia ni infestation [48]. In this study, we found that the effects of HIPVs released from S. litura-infested Chinese cabbage on the selection behavior of S. litura and M. similis differed depending on the duration of the infestation. When the plants were infested by S. litura larvae for $12 \mathrm{~h}$, the released volatiles significantly affected host location by M. similis but not by S. litura (Figures $1 \mathrm{c}$ and $2 \mathrm{~d}$ ). After the plants were infested by $S$. litura for $12 \mathrm{~h}$, the release of (Z)-3-hexen-1-ol, (Z)-3-hexenyl acetate, ally isothiocyanate, linalool, and octadecane increased relative to levels in healthy plants; limonene was detected only with infested plants, and butane,1-isothiocyanato only appeared after infestation for $12 \mathrm{~h}$. However, S. litura showed a reduced preference for plants that were infested by S. litura larvae for $24 \mathrm{~h}$ (Figure 2d). The release of (Z)-3-hexen-1-ol, butane, 1-isothiocyanato, (Z)-3-hexenyl acetate, and linalool was highest after $12 \mathrm{~h}$ of $S$. litura infestation and then gradually decreased. Release of 2-hexenal, (Z)-3-hexen-1-ol, (Z)-3-hexenyl acetate, and linalool was higher early during $S$. litura infestation than later during $S$. litura infestation. The release of nonanal, pentadecane, heptadecane and octadecane increased with the infesting time of S. litura. Chinese cabbages were able to reduce their attractiveness to $S$. litura larvae after they had been infested for $24 \mathrm{~h}$ but not for $12 \mathrm{~h}$. This is because plants require time for their resistance genes to recognize the effectors of herbivorous insects and to induce immune responses [49]. Plants differ in their immune response times, and Chinese cabbage in our experiment required $24 \mathrm{~h}$ to produce an immune response.

Correlation analysis indicated that the selection rates of $M$. similis and S. litura were affected by volatile class and identity. The results showed that the increased release of limonene, linalool, and hexadecane increased the attractiveness of plant tissue to M. similis but that the increased release of $(E)$-2-hexenal and 1-Butene, 4-isothiocyanato reduced the attractiveness of plant tissue to $M$. similis. The increased release of $(E)$-2-hexenal, 1-Butene, 4-isothiocyanato, and decanal increased the attractiveness of plant tissue to S. litura, but the increased release of limonene, nonanal, hexadecane, heptadecane, and octadecane reduced the attractiveness of plant tissue to S. litura. We can find the herbivore and the parasitoid are expressing opposite attraction to some volatiles; it has become clear that plants respond to arthropod herbivory with the induced production of volatiles, but because they have different degrees of evolution in three trophic level interactions (tritrophic interaction), the effects of HIPVs on S. litura and M. similis would also be different. Plants release specific volatile substances to affect the behavior of different insects to protect themselves. In addition, the difference in recognition and acceptance of the same HIPVs between S. litura and M. similis is mainly due to their different olfactory recognition system.

Some of the volatiles detected in our research have been found to affect insect behavior in previous studies. For example, linalool elicits a strong olfactory response in the parasitoid Anagrus nilaparvatae, and 2-hexenal elicited a strong electroantennogram (EAG) response of meadow moth and Anomala corpulenta $[50,51]$. Glucosinolates are unique sulfur-containing secondary metabolites of cruciferous plants; one of the main decomposition products of Glucosinolates is 1-Butene, 4-isothiocyanato, which plays a role in host location by the herbivorous insects Plutella xylostella and Phyllotreta vittula [52-54]. Decanal, a deca-carbon aldehyde, is attractive to Phthorimaea operculella and Locusta migratoria [55]. The HIPVs contain a complex mixture of many compounds, the composition of which may vary with herbivore species, herbivore developmental instar, plant tissue, and abiotic conditions [56,57]. Recent research has shown that HIPVs could be utilized in agriculture in different strategies [58]. These compounds can be used singly or in combination to dispense volatile chemicals that affect arthropod foraging behavior; apply inducing agents that alter the attractiveness of plants; breed for or otherwise create crops with enhanced volatile emissions through genetic engineering, thus producing better synergistic effects on 
parasitoid/herbivore attractions. In order to understand how these compounds affected the behavior of $M$. similis and S. litura, we need to determine whether these compounds standard affect the behavior of $M$. similis and $S$. litura. Although our results indicate that HIPVs can attract $M$. similis and repel $S$. litura, the molecular mechanisms underlying herbivore-induced direct and indirect defenses remain to be determined.

Supplementary Materials: The following supporting information can be downloaded at: https: //www.mdpi.com/article/10.3390/insects13010073/s1, Table S1: Volatiles released by Chinese cabbage plants as affected by six treatments.

Author Contributions: Conceptualization, G.C., X.-B.S. and G.-H.H.; methodology, X.-B.S., Y.-W.D. and G.-H.H.; validation, Y.-W.D., L.-C.Z. and G.-G.Y.; investigation, Y.-W.D., L.-C.Z. and G.-G.Y.; data curation, Y.-W.D., W.-W.Z. and L.-C.Z.; writing-original draft preparation, Y.-W.D. and X.-B.S.; writing-review and editing, Y.-W.D., L.-C.Z., W.-W.Z. and G.-G.Y.; supervision, G.C., W.-W.Z. and G.-H.H.; project administration, G.C.; funding acquisition, G.C. All authors have read and agreed to the published version of the manuscript.

Funding: This research was funded by the National Natural Science Foundation of China (32172408, 31801799), the Hunan Province Natural Science Foundation (2019JJ50274), the Scientific Research Fund of Hunan Provincial Education Department (18B123), and China Agricultura Research System (CARS-23-C08).

Institutional Review Board Statement: This study does not need ethical needs, exclude this statement.

Informed Consent Statement: The study did not involve humans, exclude this statement.

Data Availability Statement: Data is contained within the article or supplementary material. The data presented in this study are available in [Table S1].

Acknowledgments: We would like to thank Bruce for English language editing. This work was supported by the National Natural Science Foundation of China $(32172408,31801799)$, the Hunan Province Natural Science Foundation (2019JJ50274), the Scientific Research Fund of Hunan Provincial Education Department (18B123), and China Agricultura Research System (CARS-23-C08).

Conflicts of Interest: The authors declare no conflict of interest.

\section{References}

1. Horiuchi, J.I.; Arimura, G.I.; Ozawa, R.; Shimoda, T.; Takabayashi, J.; Nishioka, T. A comparison of the responses of Tetranychus urticae (Acari: Tetranychidae) and Phytoseiulus persimilis (Acari: Phytoseiidae) to volatiles emitted from lima bean leaves with different levels of damage made by T. urticae or Spodoptera exigua (Lepidoptera: Noctuidae). Appl. Entomol. Zool. 2003, $38,109-116$.

2. Kanchiswamy, C.; Malnoy, M.; Maffei, M. Chemical diversity of microbial volatiles and their potential for plant growth and productivity. Front. Plant Sci. 2015, 6, 151. [CrossRef]

3. Fincheira, P.; Quiroz, A.; Tortella, G.; Diez, M.; Rubilar, O. Current advances in plant-microbe communication via volatile organic compounds as an innovative strategy to improve plant growth. Microbiol. Res. 2021, 247, 26726. [CrossRef] [PubMed]

4. Howe, G.; Jander, G. Plant immunity to insect herbivores. Annu. Rev. Plant Biol. 2008, 59, 41-66. [CrossRef] [PubMed]

5. Schuman, M.C.; Baldwin, I.T. The layers of plant responses to insect herbivores. Annu. Rev. Entomol. 2006, 61, 373-394. [CrossRef] [PubMed]

6. Walling, L.L. The myriad plant responses to herbivores. J. Plant Growth Regul. 2000, 19, 195-216. [CrossRef]

7. Leitner, M.; Boland, W.; Mithöfer, A. Direct and indirect defences induced by piercing-sucking and chewing herbivores in Medicago truncatula. New Phytol. 2005, 167, 597-606. [CrossRef]

8. Mumm, R.; Posthumus, M.A.; Dicke, M. Significance of terpenoids in induced indirect plant defence against herbivorous arthropods. Plant Cell Environ. 2008, 31, 575-585. [CrossRef]

9. War, A.; Sharma, H.; Paulraj, M.; War, M.; Ignacimuthu, S. Herbivore induced plant volatiles: Their role in plant defense for pest management. Plant Signal. Behav. 2011, 6, 1973-1978. [CrossRef]

10. Kessler, A.; Baldwin, T. Defensive function of herbivore-induced plant volatile emissions in nature. Science 2001, 291, 2141-2144. [CrossRef]

11. Yosra, C.; Diane, L.; Turlings, T.C.J.; Desurmont, G.A. Impact of exotic insect herbivores on native tritrophic interactions: A case study of the African cotton leafworm, Spodoptera littoralis and insects associated with the field mustard Brassica rapa. J. Ecol. 2015, $103,109-117$. 
12. Desurmont, G.A.; Xu, H.; Turlings, T.C.J. Powdery mildew suppresses herbivore-induced plant volatiles and interferes with parasitoid attraction in Brassica rapa. Plant Cell Environ. 2016, 39, 1920-1927. [CrossRef]

13. Turlings, T.C.J.; Tumlinson, J.H.; Lewis, W.J. Exploitation of herbivore-induced plant odors by host-seeking parasitic wasps. Science 1990, 250, 1251-1253. [CrossRef]

14. Hare, J.D.; Sun, J.J. Production of induced volatiles by Datura wrightii in response to damage by insects: Effect of herbivore species and time. J. Chem. Ecol. 2011, 37, 751-764. [CrossRef]

15. Stam, J.M.; Kroes, A.; Li, Y.; Gols, R.; Van Loon, J.J.A.; Poelman, E.H.; Dicke, M. Plant interactions with multiple insect herbivores: From community to genes. Annu. Rev. Plant Biol. 2014, 65, 689-713. [CrossRef]

16. Gish, M.; De Moraes, C.M.; Mescher, M.C. Herbivore-induced plant volatiles in natural and agricultural ecosystems: Open questions and future prospects. Insect Sci. 2015, 9, 1-6. [CrossRef]

17. Veyrat, N.; Robert, C.A.M.; Turlings, T.C.J.; Erb, M. Herbivore intoxication as a potential primary function of an inducible volatile plant signal. J. Ecol. 2016, 104, 591-600. [CrossRef]

18. Turlings, T.C.J.; Tumlinson, J.H. Do parasitoids use herbivore-induced plant chemical defences to locate hosts? Fla. Entomol. 1991, 74, 42-50. [CrossRef]

19. Signoretti, A.G.C.; Peñaflor, M.F.G.V.; Bento, J.M.S. Fall Armyworm, Spodoptera frugiperda (J.E. Smith) (Lepidoptera: Noctuidae), female moths respond to herbivore-induced corn volatiles. Neotrop. Entomol. 2012, 41, 22-26. [CrossRef]

20. Carroll, M.J.; Schmelz, E.A.; Meagher, R.L.; Teal, P.E.A. Attraction of Spodoptera frugiperda Larvae to Volatiles from HerbivoreDamaged Maize Seedlings. J. Chem. Ecol. 2006, 32, 1911-1924. [CrossRef]

21. Tatemoto, S.; Shimoda, T. Olfactory responses of the predatory mites (Neoseiulus cucumeris) and insects (Orius strigicollis) to two different plant species infested with onion thrips (Thrips tabaci). J. Chem. Ecol. 2008, 34, 605-613. [CrossRef]

22. Pan, M.Z.; Liu, T.X. Suitability of three aphid species for Aphidius gifuensis (Hymenoptera: Braconidae): Parasitoid performance varies with hosts of origin. Biol. Control 2014, 69, 90-96. [CrossRef]

23. De Moraes, C.M.; Lewis, W.J.; Paré, P.W.; Alborn, H.T.; Tumlinson, J.H. Herbivore-infested plants selectively attract parasitoids. Nature 1998, 393, 570-573. [CrossRef]

24. Shiojiri, K.; Ozawa, R.; Matsui, K.; Sabelis, M.W.; Takabayashi, J. Intermittent exposure to traces of green leaf volatiles triggers a plant response. Sci. Rep. 2012, 2, 378. [CrossRef]

25. Yang, S.S.; Sun, W.; Lv, J.P.; Kuang, R.P. Use of sex pheromone for control of Spodoptera litura (Lepidoptera: Noctuidae). J. Entomol. Res. Soc. 2009, 11, 27-36.

26. Li, S.J.; Huang, J.P.; Chang, Y.Y.; Quan, S.Y.; Yi, W.T.; Chen, Z.S.; Liu, S.Q.; Cheng, X.W.; Huang, G.H. Development of Microplitis similis (Hymenoptera: Braconidae) on two candidate host species, Spodoptera litura and Spodoptera exigua (Lepidoptera: Noctuidae). Fla. Entomol. 2015, 98, 736-741. [CrossRef]

27. Yi, S.J.; Hopkins, R.J.; Chen, X.Y.; Chen, Z.M.; Wang, X.; Huang, G.H. Effects of temperature on the development and fecundity of Microplitis similis (Hymenoptera: Braconidae), a parasitoid of Spodoptera litura (Lepidoptera: Noctuidae). Physiol. Entomol. 2020, 45, 95-102. [CrossRef]

28. Li, Z.Q.; Song, X.H.; Wang, M.; Wang, S.; Huang, G.H. Melanization induced by Heliothis virescens ascovirus 3 h promotes viral replication. Insect Sci. 2021, 28, 472-484. [CrossRef] [PubMed]

29. Turlings, T.C.J.; Mccall, P.J.; Alborn, H.T.; Tumlinson, J.H. An elicitor in caterpillar oral secretions that induces corn seedlings to emit chemical signals attractive to parasitic wasps. J. Chem. Ecol. 1993, 19, 411-425. [CrossRef]

30. Turlings, T.C.J.; Davison, A.; TamÒ, C. A six-arm olfactometer permitting simultaneous observation of insect attraction and odor trapping. Physiol. Entomol. 2004, 29, 45-55. [CrossRef]

31. Ahuja, I.; Rohloff, J.; Bones, A. Defence mechanisms of Brassicaceae: Implications for plant-insect interactions and potential for integrated pest management. A review. Agron. Sustain. Dev. 2010, 30, 311-348. [CrossRef]

32. Bi, J.L.; Felton, G.W. Foliar oxidative stress and insect herbivory: Primary compounds, secondary metabolites, and reactive oxygen species as components of induced resistance. Chem. Ecol. 1995, 21, 1511-1530. [CrossRef]

33. Karban, R.; Myers, J.H. Induced plant responses to herbivory. Annu. Rev. Ecol. Syst. 1989, 20, 331-348. [CrossRef]

34. Heil, M.; Koch, T.; Hilpert, A.; Fiala, B.; Boland, W.; Linsenmair, K.E. Extrafloral nectar production of the ant-associated plant, Macaranga tanarius, is an induced, indirect, defensive response elicited by jasmonic acid. Proc. Natl. Acad. Sci. USA 2001, 98, 1083-1088. [CrossRef] [PubMed]

35. Riefler, J.; Nowak, J.; Koschier, E.H. Components of essential oils in plant protection. Z. Arznei-Gewurzpflanzen 2009, 14, 70-76.

36. Kong, W.N.; Wang, Y.; Guo, Y.F.; Chai, X.H.; Li, J.; Ma, R.Y. Behavioral effects of different attractants on adult male and female oriental fruit moths, Grapholita molesta. Pest Manag. Sci. 2020, 76, 3225-3235. [CrossRef]

37. Pashalidou, F.G.; Eyman, L.; Sims, J.; Buckley, J.; Fatouros, N.E.; De Moraes, C.M.; Mescher, M.C. Plant volatiles induced by herbivore eggs prime defences and mediate shifts in the reproductive strategy of receiving plants. Ecol. Lett. 2020, 13, 1097-1106. [CrossRef] [PubMed]

38. Xiu, C.; Pan, H.; Liu, B.; Luo, Z.; Williams, L.; Yang, Y.; Lu, Y. Perception of and Behavioral Responses to Host Plant Volatiles for Three Adelphocoris Species. J. Chem. Ecol. 2019, 45, 779-788. [CrossRef] [PubMed]

39. Renwick, J.A.A. OvIposition behavior in lepidoptera. Annu. Rev. Entomol. 1994, 39, 377-400. [CrossRef]

40. Staudt, M.; Lhoutellier, L. Volatile organic compound emission from holm oak infested by gypsy moth larvae: Evidence for distinct responses in damaged and undamaged leaves. Tree Physiol. 2007, 27, 1433-1440. [CrossRef] 
41. Arab, A.; Bento, J. Plant volatiles: New perspectives for research in Brazil. Neotrop. Entomol. 2006, 35, 151-158. [CrossRef] [PubMed]

42. Alborn, H.; Turlings, T.; Jones, T.; Stenhagen, G.; Loughrin, J.; Tumlinson, J. An Elicitor of Plant Volatiles from Beet Armyworm Oral Secretion. Science 1997, 276, 945-949. [CrossRef]

43. Gao, Y.; Luo, L. Research progress in tritrophic interactions among host plants, the beet armyworm Spodoptera exigua (Hübner) (Lepidoptera: Noctuidae) and its parasitoids. Acta Entomol. Sin. 2006, 49, 333-341.

44. Musser, R.O.; Hum-Musser, S.M.; Sue, M.; Eichenseer, H.; Peiffer, M.; Ervin, G.; Murphy, J.B.; Felton, G.W. Herbivory: Caterpillar saliva beats plant defences. Nature 2002, 416, 599-600. [CrossRef]

45. Lange, E.S.D.; Laplanche, D.; Guo, H.; Xu, W.; Turlings, T.C.J. Spodoptera frugiperda Caterpillars Suppress Herbivore-Induced Volatile Emissions in Maize. J. Chem. Ecol. 2020, 46, 344-360. [CrossRef]

46. Hare, J.D. Ecological role of volatiles produced by plants in response to damage by herbivorous insects. Annu. Rev. Entomol. 2011, 56, 161-180. [CrossRef]

47. Nachappa, P.; Margolies, D.C.; Nechols, J.R.; Loughin, T. Phytoseiulus persimilis response to herbivore-induced plant volatiles as a function of mite-days. Exp. Appl. Acarol. 2006, 40, 231-239. [CrossRef]

48. Miresmailli, S.; Gries, R.; Gries, G.; Zamarc, R.H.; Ismand, M.B. Population density and feeding duration of cabbage looper larvae on tomato plants alter the levels of plant volatile emissions. Pest Manag. Sci. 2011, 68, 101-107. [CrossRef] [PubMed]

49. Yu, H.; Ye, W.; Sun, M.; Xu, N.; Lou, S.; Ran, J.; Lou, Y. Three levels of defense and anti-defense responses between host plants and herbivorous insects. Chin. J. Ecol. 2015, 34, 256-262.

50. Xie, M.; Chen, H.; Yi, J.; Li, K.; Zhang, J.; Su, W. Electroantennographic and behavioral responses of Anomala corpulenta to plant volatiles. Plant Prot. 2015, 41, 33-38.

51. Zhang, Y.; Li, T.; Mo, J. The attractiveness of rice plant volatiles to Apanteles chilonis Munakata and Anagrus nilaparvatae Pang et Wang. Chin. J. Appl. Entomol. 2016, 53, 491-498.

52. Fahey, J.W.; Zalcmann, A.T.; Talalay, P. The chemical diversity and distribution of glucosinolates and isothiocyanates among plants. Phytochemistry 2001, 56, 5-51. [CrossRef]

53. Tóth, M.; Csonka, É; Bartelt, R.J.; Cossé, A.A.; Zilkowski, B.W. Similarities in pheromonal communication of flea beetles Phyllotreta cruciferae Goeze and Ph. vittula Redtenbacher (Coleoptera, Chrysomelidae). Curr. Opin. Insect Sci. 2011, 136, 688-697.

54. Liu, X.L.; Zhang, J.; Yan, Q.; Miao, C.L.; Han, W.K.; Hou, W.; Yang, K.; Hansson, B.S.; Peng, Y.C.; Guo, J.M.; et al. The molecular basis of host selection in a crucifer-specialized moth. Curr. Biol. 2020, 30, 4476-4482. [CrossRef]

55. Li, X.; Zhang, X.G.; Xiao, C.; Gao, Y.L.; Dong, W.X. Behavioral responses of potato tuber moth (Phthorimaea operculella) to tobacco plant volatiles. J. Integr. Agric. 2020, 19, 325-332. [CrossRef]

56. Takabayashi, J.; Dicke, M.; Posthumus, M. Volatile herbivore-induced terpenoids in plant-mite interactions: Variation caused by biotic and abiotic factors. J. Chem. Ecol. 1994, 6, 1329-1354. [CrossRef]

57. Gouinguené, S.; Degen, T.; Turlings, T. Variability in herbivore-induced odour emissions among maize cultivars and their wild ancestors (teosinte). Chemoecology 2001, 1, 9-16. [CrossRef]

58. Turlings, T.; Erb, M. Tritrophic Interactions Mediated by Herbivore-Induced Plant Volatiles: Mechanisms, Ecological Relevance, and Application Potential. Annu. Rev. Entomol. 2018, 63, 433-452. [CrossRef] [PubMed] 